\title{
Adverse birth outcomes among women who gave births at Eastern Ethiopian Hospitals: a cross sectional study
}

Teshale Mulatu Dibisa ( $\sim$ woyesag@gmail.com )

Haramaya University College of Health and Medical Sciences https://orcid.org/0000-0002-5134-6701

Adera Debela Kebede

Haramaya University College of Health and Medical Sciences

Tilaye Feto Gelano

Haramaya University College of Health and Medical Sciences

Yadeta Dessie Bacha

Haramaya University College of Health and Medical Sciences

Kemal Jemal

Salale University

Research article

Keywords: Adverse birth outcome, stillbirth, preterm birth, low birth weight

Posted Date: May 13th, 2020

DOl: https://doi.org/10.21203/rs.3.rs-22703/v1

License: (9) This work is licensed under a Creative Commons Attribution 4.0 International License.

Read Full License 


\section{Abstract \\ Background}

Adverse births outcomes (ABO) such as preterm birth, low birth weight (LBW) and stillbirth are important determining of neonatal morbidity and mortality. It is the major public health problem in low resourced countries. Despite many efforts to reduce neonatal morbidity and mortality, adverse birth outcomes in hospitals has remained high. Therefore, this study aimed to assess the prevalence and factors associated with adverse birth outcomes among women who gave birth at selected public hospitals in Eastern Ethiopia.

\section{Methods}

Facility based cross-sectional study design was conducted in February 2017. Data were collected using a pretested and structured face to face interviewer-administered questionnaire. Binary logistic regression was used to analyze the association between the dependent and independent variables.

\section{Results}

A total of 555 women who give births were involved from four hospitals in Eastern Ethiopia. The prevalence of low birth weight, stillbirth and preterm births were $40(7.2 \%), 37(6.7 \%)$ and $28(5 \%)$ respectively. The overall prevalence of adverse birth outcomes was 76(13.7\%). Four-ninth 247(44.5\%) of mothers had high-risk pregnancies. Hypertension [AOR $=7.25 ; 95 \%, \mathrm{Cl}=(1.71,30.64)]$, history of adverse birth outcome $[\mathrm{AOR}=12.12 ; 95 \%, \mathrm{Cl}=(6.5,22.6)]$, multiple pregnancy $[\mathrm{AOR}=6.94 ; 95 \%, \mathrm{Cl}=(2.74,17.53)]$ and spontaneous vaginal delivery $[A O R=0.11 ; 95 \%, C l=(0.44,0.16)]$ were associated with adverse birth outcome.

\section{Conclusion}

In this study adverse birth outcomes were still found as public health problems. Hypertension, history of adverse birth outcome, multiple pregnancy and spontaneous vaginal delivery were significantly associated with ABO. Thus, developing strategies to prevent and treat complications during pregnancy and increasing maternal health utilization at ANC clinics are warranted.

\section{Background}

Adverse birth outcomes are the most health problem that leads to neonatal morbidity and mortality over the world. It includes preterm birth, low birth weight (LBW), and stillbirth(1). Worldwide, around 15 million preterm babies are born every year. Almost $35 \%$ of neonatal mortality is related to preterm birth and $99 \%$ occur in low-income countries $(2,3)$. 
In resourced countries, the rate of stillbirth is 3 to 4 per thousand births, whereas 10 folds higher in low resourced countries(4). Around 3.3 million stillbirths occurred in low resourced countries. In sub-Saharan Africa, an estimated 900,000 babies die due to stillbirths and two-thirds of all stillbirth mortality happened before the onset of labor, or antepartum stillbirths(5).

Low birth weight (LBW) also the leading cause of neonatal death. It is a major contributor to infant and under-five mortality. Globally, greater than 20 million infants are born LBW (15.5\% of all births) which $95.6 \%$ are in low resourced countries(6).

Early and late morbid conditions like coronary heart disease, non-insulin dependent diabetes, childhood hypertension, behavioral disorders, impaired cognitive function, psychological disorders and long-term financial burden are risk factors associated with LBW(7).

In Ethiopia, a high rate of neonatal mortality is reported and preterm birth is a major and direct cause of neonatal mortality. According to the Ethiopian demographic health survey (EDHS-2016), a five years profile of infant and child mortality indicated that the neonatal mortality rate was declined from 49 deaths per 1,000 live births in 2000 to 29 deaths per 1,000 births in 2016(8).

Despite numerous strategies and interventions, prevention of adverse birth outcomes have remained largely unaddressed. In general, epidemiological data on the magnitude and risk factors of adverse birth outcomes are limited in the study area. Therefore, this study aimed to determine the prevalence and associated factors of adverse birth outcomes at selected public hospitals in Eastern Ethiopia.

\section{Methods}

A facility based cross-sectional study design was employed in February 2017 at Eastern Ethiopia Public Hospitals. Four Hospitals: Hiwot Fana Specialized University Hospital, Chiro Hospital, Karamara Hospital and Dilchora Hospital were selected randomly from Harari regional state, Oromiya regional state, Somali regional state, and Dire Dawa city Administrative respectively(9-12). All women who gave birth in the selected study hospitals during data collection period were included in this study. Women with serious illness who were unable to respond were excluded

\section{Data collection tools and procedure:}

A pretested and standardized face-to-face interviewer-administered questionnaire was used to collect data. The questionnaire contains socio-demographic characteristics, maternal and obstetric history, and history of chronic diseases. Data collection tool was prepared in English and translated to local languages (Amharic, Afan Oromo, and Somali) for administration and then translated back to English to maintain consistency. Four Diploma Midwives and two Bsc Midwives who were fluently speaking local language were recruited for data collection and supervision respectively. 
The current pregnancy outcomes were dichotomized into favorable birth outcomes and adverse birth outcomes. Favorable birth outcome considered if the delivery resulted in a live term baby with normal birth weight. Adverse Birth Outcome refers delivery of preterm birth (between 28 and 37 weeks gestation calculated from LNMP or early ultrasound reading), low birth weight(less than $2500 \mathrm{~g}$ after delivery) or stillbirth (any fetus born at 28 weeks gestational age or more with no heartbeat or respiratory effort after viability) $(6,13,14)$.

\section{Data processing and analysis:}

The collected data were entered into the computer by using Epi info-version 7. Data cleaning and analysis was done using SPSS-version 20. Bivariate and multivariate logistic regression analysis was used to analyze the association between the dependent and independent variables. Hosmer-Lemeshow's and Omnibus tests were done to test for model fitness. Bivariate logistic regression was used to identify predictors of adverse birth outcomes. All variables with $p$-value $\leq 0.2$ were taken into the multivariable model to control for all possible confounders. Finally, the results of multivariable logistic regression analysis were presented in crude and adjusted odds ratios with $95 \%$ confidence intervals. The level of statistical significance was declared at a p-value of less than 0.05 .

\section{Ethical considerations:}

Ethical clearance for the study was obtained from the Institute of Health Research and Ethical Review Committee of Haramaya University College of Medical and Health Sciences, regarding written and fingerprint consent, the privacy of participants, risk and benefit analysis of the study were approved. Informed voluntary written and fingerprint consent was obtained from study participants after explaining the purpose and procedure of the study.

\section{Results}

A total of 555 study participants were participated in this study. The mean age was 26.6 ( \pm standard deviation $=4.62$ ) years. The majority were Muslim $(65.8 \%)$, and $(63.6 \%)$ of study subjects were Oromo ethnics. Most (94.7\%) of study participants were married, and more than half $(51.4 \%)$ were housewives. One third (33.3\%) of the participants had no formal education. The mean age at first marriage was 20.8 $( \pm$ standard deviation $=3.5)$ years $($ Table 1$)$. 
Table 1

Socio-demographic characteristics of study participants at selected public hospitals in Eastern Ethiopia, $2017(n=555)$.

\begin{tabular}{|c|c|c|}
\hline Variables & Frequency & Percentages \\
\hline \multicolumn{3}{|l|}{ Age } \\
\hline$<20$ & 192 & 34.6 \\
\hline $20-34$ & 339 & 61.1 \\
\hline $35+$ & 24 & 4.3 \\
\hline \multicolumn{3}{|l|}{ Residence } \\
\hline Rural & 218 & 39.3 \\
\hline Urban & 337 & 60.7 \\
\hline \multicolumn{3}{|c|}{ Marital status } \\
\hline Married & 526 & 94.7 \\
\hline Single & 29 & 5.3 \\
\hline \multicolumn{3}{|c|}{ Age at first birth } \\
\hline$\leq 20$ & 220 & 39.6 \\
\hline$>20$ & 335 & 60.4 \\
\hline \multicolumn{3}{|l|}{ Ethnicity } \\
\hline Oromo & 353 & 63.6 \\
\hline Amhara & 120 & 21.6 \\
\hline Somali & 46 & 8.3 \\
\hline Harari & 26 & 4.7 \\
\hline Others* & 10 & 1.8 \\
\hline \multicolumn{3}{|l|}{ Religion } \\
\hline Muslim & 365 & 65.8 \\
\hline Orthodox & 159 & 28.6 \\
\hline Protestant & 27 & 4.9 \\
\hline Others** & 4 & 0.7 \\
\hline
\end{tabular}

Others*Tigre, Gurage and Walaitta; Others ${ }^{\star \star}$ Catholic and Adventist; Others ${ }^{\star \star \star}$ Waiter, Daily laborer, housemaid. 


\begin{tabular}{|lll|}
\hline Variables & Frequency & Percentages \\
\hline No formal education & 185 & 33.3 \\
\hline Primary school & 152 & 27.4 \\
\hline Secondary school & 112 & 20.2 \\
\hline College/university & 106 & 19.1 \\
\hline Mother occupation & & \\
\hline Housewife & 285 & 51.4 \\
\hline Government employee & 74 & 13.3 \\
\hline Private employee & 132 & 23.8 \\
\hline Merchant & 48 & 8.6 \\
\hline Others*** & 16 & 2.9 \\
\hline $\begin{array}{l}\text { Others*Tigre, Gurage and Walaitta; Others** Catholic and Adventist; Others } \\
\text { housemaid. }\end{array}$ & \\
\hline
\end{tabular}

\section{Maternal and obstetric history of study participants:}

The majority of the study participants (65.8\%) were multi-parous and $357(64.3 \%)$ of study participants had taken iron supplementation during their pregnancy follow up. Greater than three-fourth $(79.5 \%)$ of study participants had ANC follow up at least one visit (Table 2).

Follow up of ANC was assessed: majority $121(27.4 \%)$ of pregnant women had ANC four visits, on the other hand, around $61(13.8 \%)$ of pregnant mothers had merely one follow up before the onset of delivery. The frequencies of ANC follow up from second to fourth visits were similar, and only 29(6.6\%) pregnant women had ANC four-plus visits (Fig. 1).

Fifth-seventh $399(71.9 \%)$ of pregnant women who participated in the study had a tetanus toxoid (TT) vaccine (Table 2). The TT vaccines protect the women from tetanus during birth if the pregnant mothers take TT2 and above. Majority $346(86.7 \%)$ of study participants had taken TT2 and above while $53(13.3 \%)$ had only one dose before their delivery from 399 participants (Fig. 2).

Greater than one-third 249(44.9\%) mothers faced obstetric complications among which the leading cause was prolonged labor $63(25.3 \%)$ followed by fetal distress $57(22.9 \%)$. About the mode of deliveries 396 (71.4\%) were spontaneous vaginal delivery and $131(23.6 \%)$ mothers gave birth via cesarean section (Table 2).

Four-ninth 247 (44.5\%) of pregnant mothers had high-risk pregnancies. From them, 16(2.9\%) study participants age at first pregnancy was greater than 35 years (Table 1). Almost greater than one-fifth 
$124(22.3 \%)$ of study subjects had existing health conditions: According to reports in the mothers' history sheet, $10(8.1 \%)$ of mothers were HIV positive, $29(23.4 \%)$ have diagnosed with hypertension, $75(60.5 \%)$ of mothers were anemic (hemoglobin level less than $11 \mathrm{gm} / \mathrm{dl}$ ). Additionally, 5(4\%) of mothers were diagnosed with diabetes mellitus (4\%) and others (like malaria, tuberculosis, cardiac disease, and genitourinary tract infections). Again, $99(17.8 \%)$ of the mothers had a previous history of adverse birth outcomes (Table 2). 
Table 2

Maternal and reproductive history of study participants at selected public hospitals in Eastern Ethiopia, $2017(n=555)$.

\begin{tabular}{|c|c|c|}
\hline Variables & Frequency & Percentage \\
\hline \multicolumn{3}{|l|}{ Parity } \\
\hline Multipara & 365 & 65.8 \\
\hline Primipara & 190 & 34.2 \\
\hline \multicolumn{3}{|l|}{ ANC follow up } \\
\hline Yes & 441 & 79.5 \\
\hline No & 114 & 20.5 \\
\hline \multicolumn{3}{|l|}{ TT vaccine } \\
\hline Yes & 399 & 71.9 \\
\hline No & 156 & 28.1 \\
\hline \multicolumn{3}{|c|}{ Iron supplementation } \\
\hline Yes & 357 & 64.3 \\
\hline No & 198 & 35.7 \\
\hline \multicolumn{3}{|l|}{ Chronic diseases } \\
\hline Yes & 124 & 22.3 \\
\hline No & 431 & 77.7 \\
\hline \multicolumn{3}{|c|}{ Types of chronic diseases $(n=124)$} \\
\hline Hypertension & 29 & 23.4 \\
\hline Diabetes Melitus & 5 & 4. 0 \\
\hline Anemia & 75 & 60.5 \\
\hline HIV & 10 & 8.1 \\
\hline others & 5 & 4.0 \\
\hline \multicolumn{3}{|c|}{ History of adverse birth outcome } \\
\hline Yes & 99 & 17.8 \\
\hline No & 456 & 82.2 \\
\hline
\end{tabular}

Others: Malaria, Tuberculosis and cardiac diseases and genitourinary diseases 


\begin{tabular}{|c|c|c|}
\hline Variables & Frequency & Percentage \\
\hline Yes & 249 & 44.9 \\
\hline No & 306 & 55.1 \\
\hline \multicolumn{3}{|c|}{ Types of obstetric complications $(n=249)$} \\
\hline Antepartum hemorrhage & 23 & 9.2 \\
\hline Multiple pregnancy & 37 & 14.9 \\
\hline PROM & 13 & 5.2 \\
\hline Pre-eclampsia/eclampsia & 36 & 14.5 \\
\hline Prolonged/obstructed labor & 63 & 25.3 \\
\hline Fetal distress & 57 & 22.9 \\
\hline Post partum hemorrhage & 20 & 8.0 \\
\hline \multicolumn{3}{|l|}{ Mode of delivery } \\
\hline Spontaneous vaginal delivery & 396 & 71.4 \\
\hline Assisted instrumental delivery & 28 & 5 \\
\hline Cesarean section & 131 & 23.6 \\
\hline \multicolumn{3}{|c|}{ Others: Malaria, Tuberculosis and cardiac diseases and genitourinary diseases } \\
\hline
\end{tabular}

\section{Prevalence of adverse birth outcome:}

The prevalence of adverse birth outcomes was $40(7.2 \%)$ of low birth weight, $37(6.7 \%)$ of stillbirth, and $28(5 \%)$ of preterm birth. Among all deliveries $76(13.7 \%)$ had resulted in the adverse birth outcomes and $479(86.3 \%)$ resulted in favorable birth outcomes (Fig. 3).

\section{Factors associated with adverse birth outcome:}

The findings from bivariate logistic regression revealed that residence, maternal education, chronic disease(hypertension), history of adverse birth outcome, multiple pregnancy, pregnancy-induced hypertension, antepartum hemorrhage and mode of delivery (spontaneous vaginal delivery) were the independent predictors of adverse birth outcomes. However, in the multivariate logistic regression analysis, hypertension, history of adverse birth outcomes, and spontaneous vaginal delivery remained significantly (Table 3 ).

Study participants who had diagnosed hypertension were seven times more likely to have adverse birth outcomes than normo-tensive women [AOR $=7.25 ; 95 \%$, Cl: $(1.71,30.64)]$. The odds of adverse birth outcome was about twelve times higher among women with a previous history of adverse birth outcome 
than those women who did not have previous history of adverse birth outcomes [AOR $=12.12 ; 95 \%, \mathrm{Cl}$ : $(6.5,22.6)]$. The odds of adverse birth outcomes were about seven times higher among women with multiple pregnancies than those women with singleton pregnancy [AOR $=6.94 ; 95 \%, \mathrm{Cl}:(2.74,17.53)]$. The odds of adverse birth outcomes were less among women who gave birth through spontaneous vaginal delivery than those women who delivered by cesearean section $[A O R=0.11 ; 95 \%, \mathrm{Cl}:(0.44,0.16)]$ (Table $3)$. 
Table 3

Bivariate and multivariate analysis of factors associated with adverse birth outcome among study participants at selected public hospitals in Eastern Ethiopia, $2017(\mathrm{n}=555)$.

\begin{tabular}{|c|c|c|c|c|}
\hline \multirow[t]{2}{*}{ Variables } & \multicolumn{2}{|c|}{ Adverse birth outcome } & \multicolumn{2}{|c|}{ Odds ratio ( $95 \%$ confidence interval) } \\
\hline & Yes & No & $\operatorname{COR}(95 \% \mathrm{Cl})$ & $\operatorname{AOR}(95 \% \mathrm{Cl})$ \\
\hline \multicolumn{5}{|l|}{ Residence } \\
\hline Rural & 41 & 177 & $1.99(1.23,3.25)$ & $1.22(0.6,2.48)$ \\
\hline Urban & 35 & 302 & 1 & \\
\hline \multicolumn{5}{|l|}{ Maternal education } \\
\hline No formal education & 39 & 146 & $1.50(0.85,2.642)$ & $0.92(0.43,1.98)$ \\
\hline Primary school & 23 & 129 & $3.06(1.4,6.58)$ & $1.65(0.59,4.59)$ \\
\hline Secondary school & 9 & 103 & $5.40(2.05,14.16)$ & $2.76(0.84,9.12)$ \\
\hline College/university & 5 & 101 & 1 & 1 \\
\hline \multicolumn{5}{|c|}{ History of chronic diseases } \\
\hline \multicolumn{5}{|l|}{ Hypertension } \\
\hline Yes & 9 & 20 & $4.38(1.207,15.89)$ & $7.25(1.71,30.64)$ \\
\hline No & 67 & 459 & 1 & 1 \\
\hline \multicolumn{5}{|c|}{ History of adverse birth outcome } \\
\hline Yes & 46 & 53 & $12.32(7.17,21.17)$ & $12.12(6.5,22.6)$ \\
\hline No & 30 & 426 & 1 & 1 \\
\hline \multicolumn{5}{|c|}{ Pregnancy/labor complications } \\
\hline \multicolumn{5}{|l|}{ Multiple pregnancy } \\
\hline Yes & 15 & 22 & $5.12(2.51,10.38)$ & $6.94(2.74,17.53)$ \\
\hline No & 61 & 457 & 1 & 1 \\
\hline \multicolumn{5}{|c|}{ Pregnancy induced hypertension } \\
\hline Yes & 13 & 23 & $4.09(1.973,8.48)$ & $1.96(0.81,4.76)$ \\
\hline No & 63 & 456 & 1 & 1 \\
\hline \multicolumn{5}{|c|}{ Ante partum hemorrhage } \\
\hline Yes & 7 & 16 & $2.94(1.17,7.4)$ & $1.16(0.37,3.64)$ \\
\hline No & 69 & 463 & 1 & 1 \\
\hline
\end{tabular}




\begin{tabular}{|c|c|c|c|c|}
\hline Variables & \multicolumn{2}{|c|}{ Adverse birth outcome } & \multicolumn{2}{|c|}{ Odds ratio (95\% confidence interval) } \\
\hline \multicolumn{5}{|l|}{ Mode of delivery } \\
\hline Spontaneous vaginal delivery & 54 & 342 & $0.33(0.14,0.78)$ & $0.11(0.44,0.16)$ \\
\hline Assisted instrumental delivery & 9 & 19 & $1.43(0.78,2.72)$ & $1.62(0.74,3.57)$ \\
\hline Cesarean section & 13 & 118 & 1 & 1 \\
\hline
\end{tabular}

\section{Discussion}

In this study, we assessed the prevalence and associated factors of adverse birth outcomes (stillbirth, preterm birth and low birth weight) among women who gave birth at selected public hospitals in Eastern Ethiopia. The overall prevalence of adverse birth outcomes among the study participants was $13.7 \%$. This finding is relatively similar with studies finding from Kembata Tembaro zone(13.9\%) (15) and Hawassa $(18.3 \%)(16)$, but lower than that of Gondar (23\%)(17), Hossana town (24.5\%) (18) and Wollo zone $(31.8 \%)(19)$. This variation may be due to the difference in the study setting, socio-cultural status, maternal and newborn health care services and various interventions undertaken between these study times.

In this study we found that $7.2 \%$ of deliveries were delivered as low birth weight babies. This finding is consistent with studies finding in Butajira (8.9\%)(18), Gondar (11.2\%)(17), and Hawassa (11.6\%)(16). However, lower than the study done in Wollo (19.5\%)(19). The possible explanation for this discrepancy may be attributable to socio-economic variations and the difference in the quality of maternal health service. Also, the variation of nutritional and cultural practices may contribute to the observed differences.

In our study $6.7 \%$ of deliveries were stillbirth. This finding is in line with that of Gondar (7.1\%)(17) and Wollo (7.8\%)(19) but higher than that of Hawassa (2.7\%)(16), Kembata Tembaro (3.3\%)(15) and Butajira $(3.5 \%)(18)$. The discrepancies may be due to methodological and population variation on top of the socio-economic and set up differences.

In this study the prevalence of preterm birth was $5 \%$. This finding is consistent with that of Hawassa (3.6\%)(16) and Butajira (6.4\%)(18) but lower than that of Wollo (13.2\%)(19) and Gondar (14.3\%)(17). The difference may be due to variation in populations and study setting and quality of maternal healthcare service.

The findings from the multiple logistic regression analysis revealed that hypertension, history of adverse birth outcomes, multiple pregnancy, and spontaneous vaginal delivery were significantly associated with adverse birth outcomes. This finding was almost found to be a universal fact and has been revealed in many studies $(16,17,20)$. 
This study showed that women who had diagnosed hypertension were statistically significant with adverse birth outcomes. This finding is in line with studies finding from china, Tanzania and Ethiopia (17, $20-22$ ). It can be justified by uteroplacental hypo-perfusion secondary to vasoconstriction which results in diminished blood supply to the fetus causing adverse fetal/birth outcome.

In our finding women with a previous history of adverse birth outcomes were significantly associated with adverse birth outcomes. This is in line with the report from other studies from china, Tanzania and Ethiopia $(16,17,21,22)$. This might be due to most bad obstetrics histories are recurrent and more likely to result in adverse birth outcome in subsequent pregnancies.

The study finding showed that women with multiple pregnancies were significantly associated with adverse birth outcomes. This finding is similar to other studies finding from Ethiopia(20,23). This might

be due to chorionicity and amniocity of placentation which is associated with fetal mortality and morbidity in monochorionic and mono amniotic twins. There was also a complication unique to twin pregnancy which is twin transfusion syndrome, discordant twin, conjoined twin, vanishing effect which increases the risk of adverse birth outcomes. The risk of anemia and pregnancy-related complications also increase in multiple pregnancies hence more likely to result in adverse birth outcomes.

The study also revealed that the odds of adverse birth outcome is less by $11 \%$ among women who gave birth through spontaneous vaginal delivery than those women who delivered by cesearean section. This finding is in contrast with other studies findings from china and WHO Multi-country Surveys $(24,25)$. The difference may be due to study setting as those two studies were large and were conducted at better health care set up were ceaseran delivery performed on elective basis without indication than the current study. Finally, as limitations the findings of this study were based on self-report, as it was not possible to validate claims made by respondents in the course of questionnaire administration.

\section{Conclusion}

Adverse birth outcome in the study area was still a publicly significant problem. Hypertension, history of adverse birth outcomes, multiple pregnancies, and spontaneous vaginal delivery were significantly associated with adverse birth outcomes. Hence, increasing access to maternal health utilization and developing strategies to prevent and treat complications during pregnancy is recommended.

\section{List Of Abbreviations}

ANC-Antenatal Care

HIV-Human Immune Deficiency Virus

LBW-Low Birth Weight

PROM-Premature Rupture Of Membrane 
SPSS-Statistical Package For Social Science

TT-Tetanus Toxoid

WHO-World Health Organization

\section{Declarations}

\section{Ethics approval and consent to participate}

Ethical approval for this study was granted from Haramaya University, College of Health and Medical Sciences, Institutional Health Research Ethics Review Committee; regarding written and fingerprint consent, the privacy of participants, risk and benefit analysis of the study (Ref.No. HURG-2016-02-04), November 03/2016 was approved. A formal letter from the college of Health and Medical sciences was submitted to all concerned bodies in the study area to secure their co-operation in facilitating the study. All the participants were asked for voluntary informed written and fingerprint consent for participation before interview initiation.

\section{Consent for publication}

N/A

\section{Availability of data and material}

The data for this study can be made available from the corresponding author when there is a reasonable need.

\section{Competing interests}

The authors declare that they have no competing interests.

\section{Funding}

This study was funded by Haramaya University as young Innovative research grant funding, a reference number for this grant: HURG-2016-02-04. The funding organization has no role in designing the study, data collection, analysis and its interpretation, protocol writing and submission.

\section{Authors' contributions}


TMD, ADK, TFG, YDB, and KJ, was conceived the study and involved in the study design, reviewed the article, analysis, report writing and drafted the manuscript. All authors have read and approved the final manuscript.

\section{Acknowledgments}

We would like to express our deepest thanks to Haramaya University research and community services affairs office for funding and supporting the study We are also grateful for study participants, data collectors, and site supervisors for their contribution.

\section{References}

1. Lawn JE, Gravett MG, Nunes TM, Rubens CE, Stanton C, Group GR. Global report on preterm birth and stillbirth (1 of 7): definitions, description of the burden and opportunities to improve data. BMC Pregnancy Childbirth. 2010;10(S1):1.

2. Beck S, Wojdyla D, Say L, Betran AP, Merialdi M, Requejo JH, et al. The worldwide incidence of preterm birth: a systematic review of maternal mortality and morbidity. Bull World Health Organ. 2010;88:31-8.

3. Blencowe H, Cousens S, Oestergaard MZ, Chou D, Moller A-B, Narwal R, et al. National, regional, and worldwide estimates of preterm birth rates in the year 2010 with time trends since 1990 for selected countries: a systematic analysis and implications. The Lancet. 2012;379(9832):2162-72.

4. McClure EM, Saleem S, Pasha O, Goldenberg RL. Stillbirth in developing countries: a review of causes, risk factors and prevention strategies. The Journal of Maternal-Fetal Neonatal Medicine. 2009;22(3):183-90.

5. Lincetto O, Mothebesoane-Anoh S, Gomez P, Munjanja S. Chapter 2; Antenatal Care: Opportunities for Africa's Newborns. Geneva: WHO; 2011.

6. Wardlaw TM. Low birthweight: country, regional and global estimates: Unicef; 2004.

7. Kayode GA, Amoakoh-Coleman M, Agyepong IA, Ansah E, Grobbee DE, Klipstein-Grobusch K. Contextual risk factors for low birth weight: a multilevel analysis. PLOS ONE. 2014;9(10).

8. Ethiopia Demographic and Health Survey. 2016: ICF International, c entral Statistical Agency, uly 2017.; 2012.

9. Hiwot Fana Specialized University Hospital Administrative. Institutional Development Office. Hiwot Fana Specialized University Hospital report 2016.

10. Western Hararghe zone Health office. Chiro hospital health care services annual report 2016.

11. Dire Dawa Adiministrative city Health Beureua. Dire Dawa adminstrative council health beureua report 2016.

12. Somali Regional Health Beureau. Somali regional health beureau report 2016. 
13. Quinn J-A, Munoz FM, Gonik B, Frau L, Cutland C, Mallett-Moore T, et al. Preterm birth: Case definition $\&$ guidelines for data collection, analysis, and presentation of immunisation safety data. Vaccine. 2016;34(49):6047-56.

14. Da Silva FT, Gonik B, McMillan M, Keech C, Dellicour S, Bhange S, et al. Stillbirth: Case definition and guidelines for data collection, analysis, and presentation of maternal immunization safety data. Vaccine. 2016;34(49):6057.

15. Lolaso T, Oljira L, Dessie Y, Gebremedhin M, Wakgari N. Adverse Birth Outcome and Associated Factors among Newborns Delivered In Public Health Institutions, Southern Ethiopia. East African Journal of Health Biomedical Sciences. 2019;3(2):35-44.

16. Tsegaye B, Kassa A. Prevalence of adverse birth outcome and associated factors among women who delivered in Hawassa town governmental health institutions, south Ethiopia, in 2017. Reproductive Health. 2018;15(1):193.

17. Adane AA, Ayele TA, Ararsa LG, Bitew BD, Zeleke BM. Adverse birth outcomes among deliveries at Gondar University hospital, Northwest Ethiopia. BMC Pregnancy Childbirth. 2014;14(1):90.

18. Abdo R, Endalemaw T, Tesso F. Prevalence and associated factors of adverse birth outcomes among women attended maternity ward at Negest Elene Mohammed Memorial General Hospital in Hosanna Town, SNNPR, Ethiopia. J Women's Health Care. 2016;5(4).

19. Kassahun EA, Mitku HD, Getu MA. Adverse birth outcomes and its associated factors among women who delivered in North Wollo zone, northeast Ethiopia: a facility based cross-sectional study. BMC Research Notes. 2019;12(1):357.

20. Adhena T, Haftu A, Gebre G, Dimtsu B. Assessment of magnitude and associated factors of adverse birth outcomes among deliveries at Suhul Hospital Shire Tigray, Ethiopia from September, 2015 to February, 2016. Res Rev J Med Sci Technol. 2017;6(1):1-10.

21. Watson-Jones D, Weiss HA, Changalucha JM, Todd J, Gumodoka B, Bulmer J, et al. Adverse birth outcomes in United Republic of Tanzania: impact and prevention of maternal risk factors. Bull World Health Organ. 2007;85:9-18.

22. Chen Y, Li G, Ruan Y, Zou L, Wang X, Zhang W. An epidemiological survey on low birth weight infants in China and analysis of outcomes of full-term low birth weight infants. BMC Pregnancy Childbirth. 2013;13(1):242.

23. Mulualem G, Wondim A, Woretaw A. The effect of pregnancy induced hypertension and multiple pregnancies on preterm birth in Ethiopia: a systematic review and meta-analysis. BMC Research Notes. 2019;12(1):91.

24. Hou L, Hellerstein S, Vitonis A, Zou L, Ruan Y, Wang X, et al. Cross sectional study of mode of delivery and maternal and perinatal outcomes in mainland China. PLOS ONE. 2017;12(2).

25. Thanh BYL, Lumbiganon P, Pattanittum P, Laopaiboon M, Vogel JP, Oladapo OT, et al. Mode of delivery and pregnancy outcomes in preterm birth: a secondary analysis of the WHO Global and Multi-country Surveys. Sci Rep. 2019;9(1):1-8. 
Figures

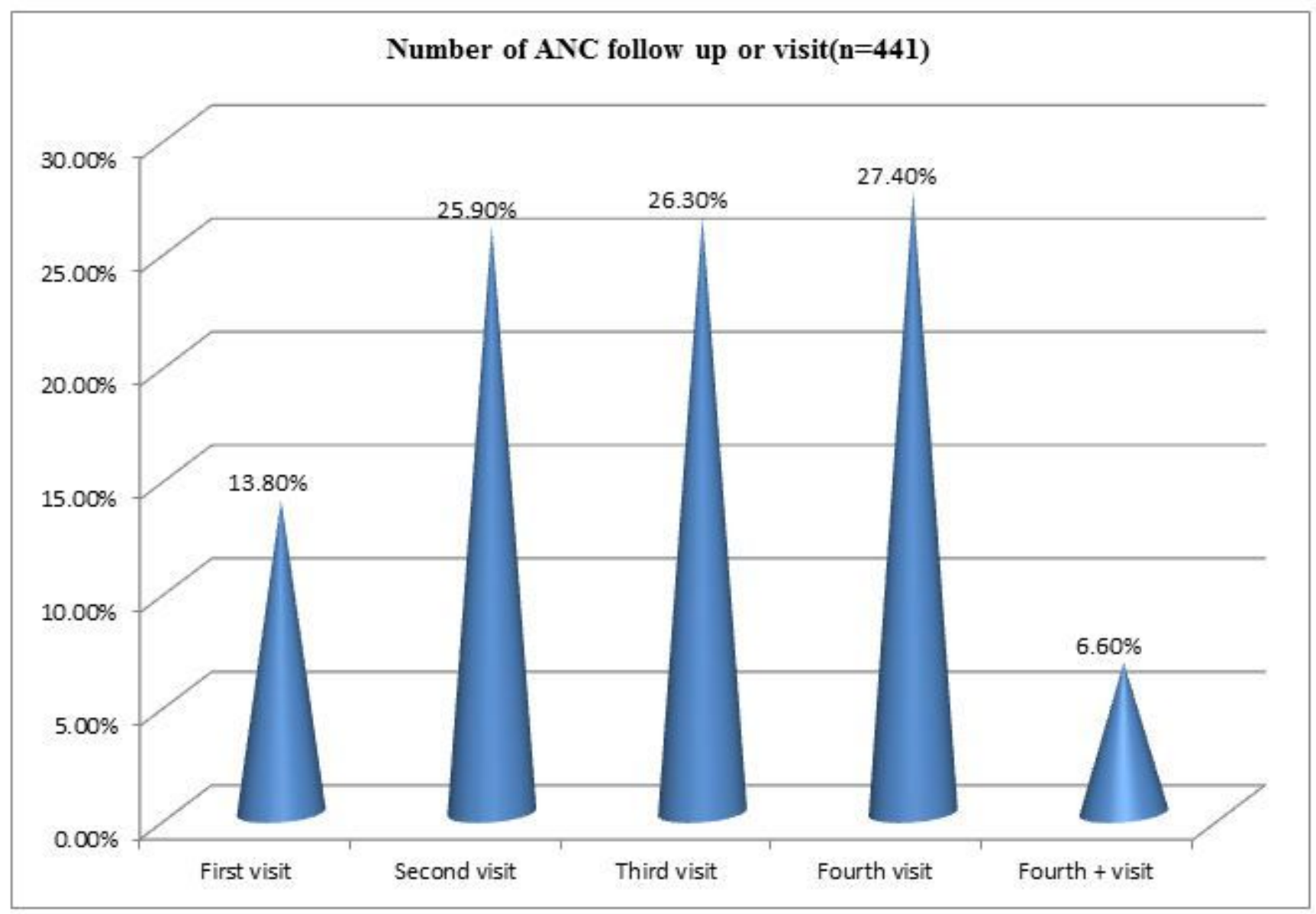

\section{Figure 1}

Number of ANC follow up or visit among study participants at selected public hospitals in Eastern Ethiopia, 2017( $n=441)$. 


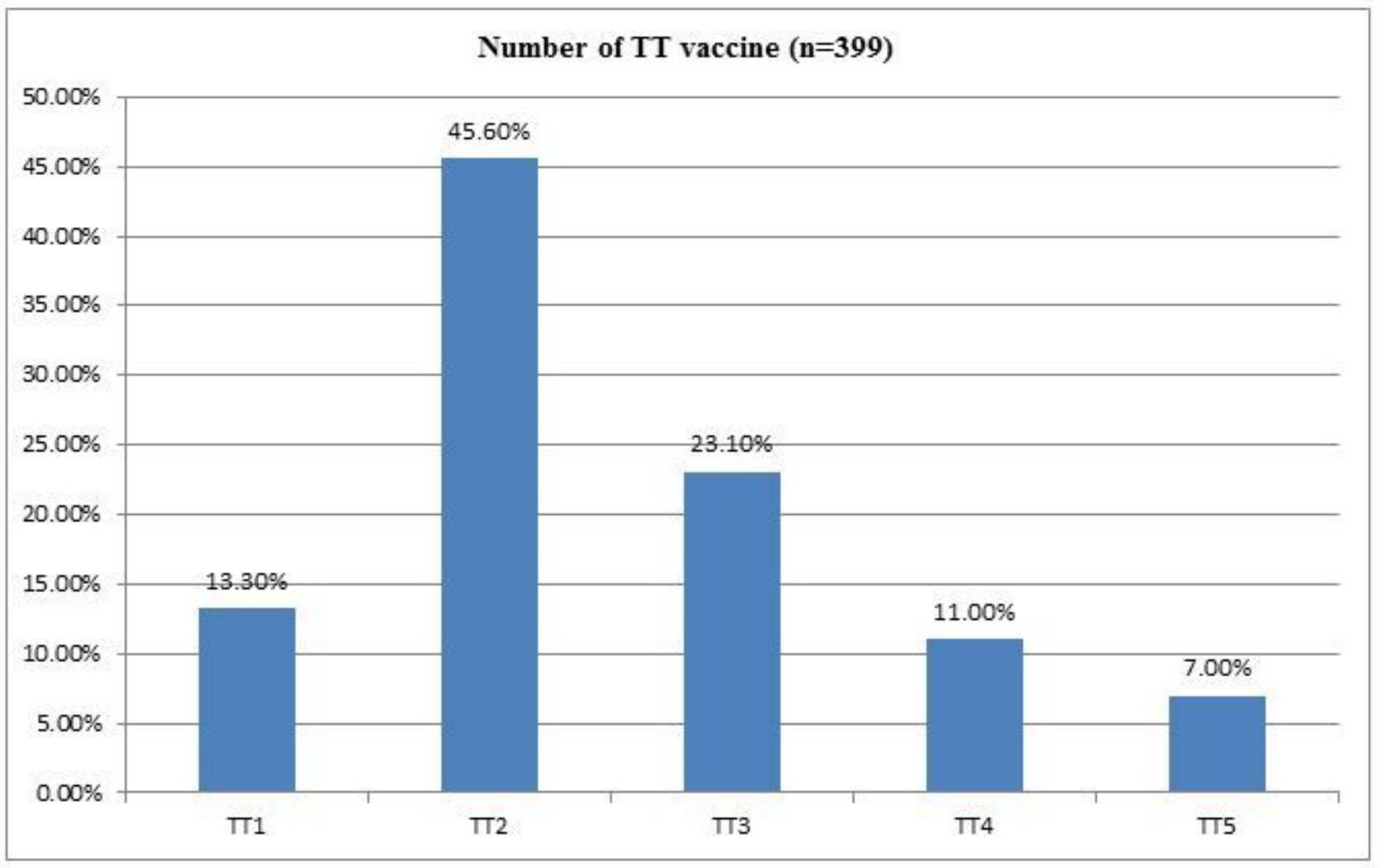

\section{Figure 2}

Number of study participants who have TT vaccine at selected public hospitals in Eastern Ethiopia, 2017 $(n=399)$.

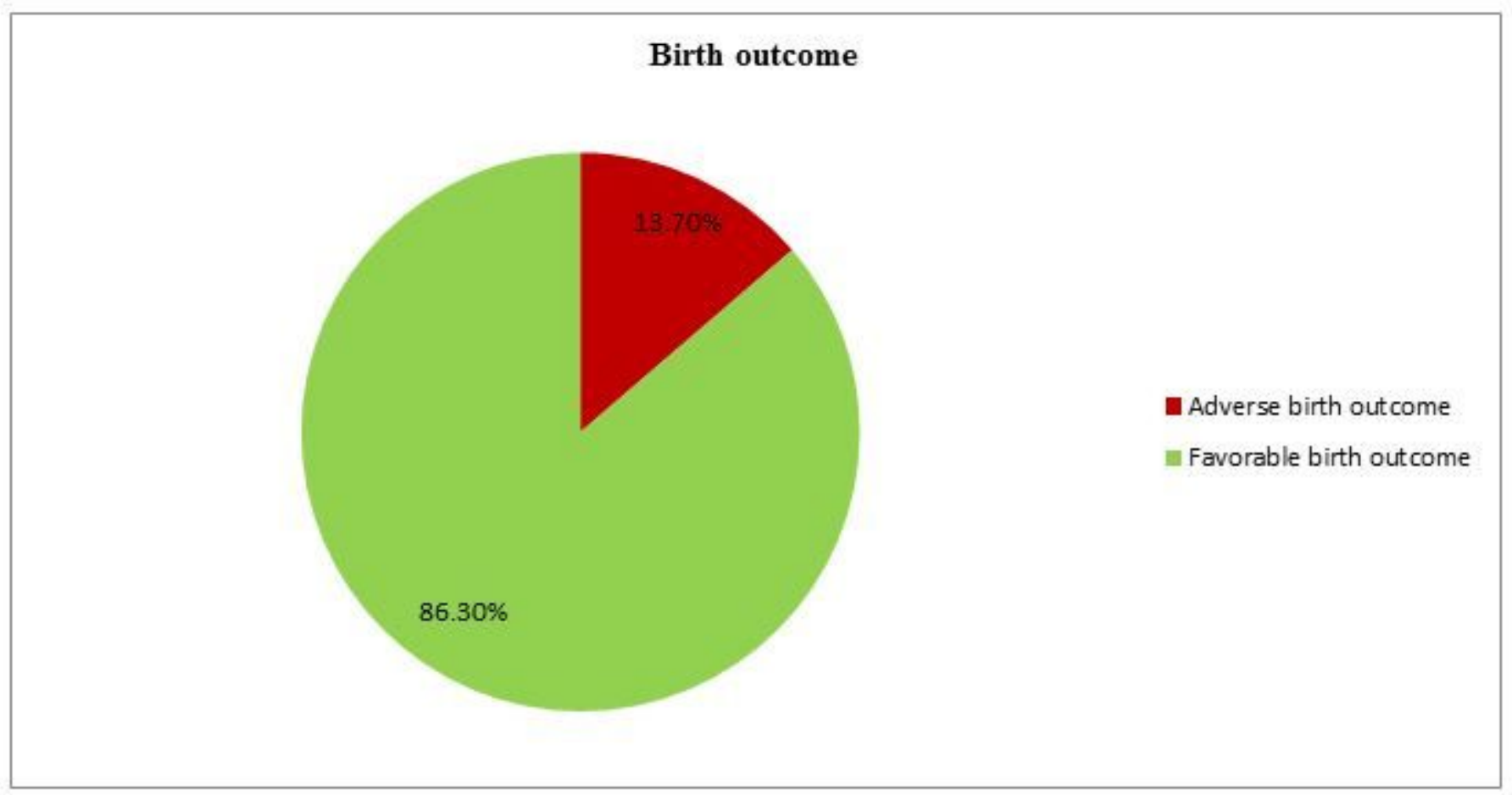

Figure 3 
The prevalence of adverse birth outcome among study participants at selected public hospitals in Eastern Ethiopia, 2017( $n=555)$. 